ЯЗЫКОЗНАНИЕ

стала чувствовать себя старухой с новым корытом (Т. Дубровская. Красная шапочка из Пскова). Новообразование имеет значение «неудержимо желать большего, чем имеешь на самом деле; неудержимая жажда нового, неизведанного».

Таким образом, окказиональные фразеологические дериваты характеризуются наличием материальных и семантических преобразований исходной ФЕ, при этом семантические преобразования затрагивают не только коннотативный, но и предметно-логический аспекты значения исходного фразеологизма. В основе же всех индивидуальноавторских фразеологизмов лежит внутренняя форма: они возникают в результате метафоризации свободных словосочетаний в процессе речи или создаются автором текста с определенной эстетической задачей.

УДК 81'373.611

Науч. спец. 10.02.20

DOI: 10.36809/2309-9380-2019-24-74-79

\section{ЗНАЧЕНИЕ НЕМЕЦКИХ ГЛАГОЛОВ, ОБРАЗОВАННЫХ ОТ НАЗВАНИЙ ЖивотнЫХ}

Настоящая статья посвящена лингвистическому анализу глаголов, образованных от названий животных в современном немецком языке. Актуальность работы обусловлена отсутствием четкой классификации отзоонимных немецких глаголов по лексическому значению. В ходе исследования автором были выделено два типа глаголов. К первому типу относятся неметафорические глаголы со значением «охотиться на животного» и «производить потомство». Ко второму типу — глаголы, которые употребляются в переносном, метафорическом значении. Последняя группа глаголов подверглась более детальной классификации, так как зоометафоры используются для определения оценочных свойств человека и его поведения.

Ключевые слова: зооглагол, зооним, оценочное значение, стилистические особенности, метафора, лексическая единица.
1. Ларин Б. А. Очерки по фразеологии // Ларин Б. А. История русского языка и общее языкознание : учеб. пособие. М. : Просвещение, 1977. С. 125-149.

2. Мокиенко В. М. Славянская фразеология. М. : Высш. шк., 1980. 207 C.

3. Фразеологический словарь русского языка / сост. : Л. А. Войнова [и др.] ; под ред. А. И. Молоткова. 6-е изд., испр. и доп. М. : Астрель: АСТ, 2001. 510 с.

4. Фразеологический словарь русского литературного языка : в 2 т. / сост. А. И. Федоров. Новосибирск : ВО «Наука», Сиб. изд. фирма, 1995. 482 с.

5. Бабкин А. М. Русская фразеология, ее развитие и источники. Л. : Наука, 1970. 263 с.

(C) Глотова Е. А., 2019

Yu. N. Goryunova

\title{
MEANING \\ OF GERMAN VERBS FORMED FROM ANIMAL NAMES
}

This article is devoted to the linguistic analysis of verbs formed from the animal names in modern German. The relevance of the work is due to the lack of a clear classification of the German verbs by lexical meaning. During the study, the author identified two types of verbs. The first type includes non-metaphorical verbs with the meaning "hunt an animal" and "produce offspring". The verbs, which are used in a figurative, metaphorical meaning, were referred to the second type. The last group of verbs has undergone a more detailed classification, since zoometaphors are used to determine the evaluative properties of a person and his behaviour.

Keywords: zoo verbs, zoonym, evaluative meaning, stylistic features, metaphor, lexical unit.

Значение животного мира для человека остается существенным на протяжении многих веков, что подтверждается данными различных языков, представляющими результаты национально-культурной концептуализации действительности. Антропоцентрический характер языковой картины мира обусловливает осмысление знаний о животных с учетом «мерки человека» (Э. Бенвенист). Включение зоонимов в систему образных средств характеристики человека, расширение и углубление знаний о самом человеке посредством сравнения, поиски сходства с образами реалий мира природы - закономерный этап развития человеческого знания о себе как об особом объекте.

В системе языка зоонимы имеют развитые словообразовательные возможности. Согласно исследованию Ю. Гэн,

больше всего отзоонимных производных представлено в виде существительных и прилагательных, а глаголов и наречий значительно меньше [1, с. 22-25]. Глаголы, образованные от зоонимов, по сравнению с существительными и прилагательными, «непродуктивны и немногочисленны и выражают два вида значений:

а) от слов, имеющих метафрорическое значение, относимое к человеку, образуются глаголы со значением 'вести себя подобно тому, кто назван производящим словом';

б) 'производить на свет' - эти глаголы создаются только от супплетивных названий детенышей» [2, с. 225-226].

Объектом настоящего исследования являются зооглаголы современного немецкого языка, такие как ӓffen (от derAffe «обезьяна») — «обезьянничать, подражать кому-либо»; 
ochsen (от der Ochse «вол») — «работать как вол»; sclängeln (от die Schlange «змея») - «извиваться» и т. д. Мы рассмотрим, свойственна ли закономерность, выявленная учеными на базе русского языка (непродуктивность в сочетании с немногочисленными типизированными значениями), и немецкому языку.

Что касается мнения о количестве и непродуктивности отзоонимных глаголов, то с этим, бесспорно, можно согласиться: в ходе анализа немецких глаголов, образованных от названий животных, нами было обнаружено только 58 лексических единиц (полный перечень представлен в приложении после текста статьи). Однако гипотеза о том, что зооглаголы выражают только два вида значений, на материале немецкого языка не нашла подтверждения их оказалось больше.

Материалом для исследования послужили глаголы, отобранные методом сплошной выборки из немецко-русских электронных словарей «Мультитран» [3] и PONS [4], а также текстовые фрагменты различных произведений немецких авторов, включающие данные лексемы. На первом этапе исследования мы разделили все отзоонимные глаголы на два типа. К первому типу относятся неметафорические глаголы со значением «охотиться на животного» и «производить потомство». Ко второму типу — глаголы, которые употребляются в переносном, метафорическом значении.

Приведем примеры. Так, специффическую, но небольшую группу составляют глаголы со значением «охотиться на животного».

Cp.: krebsen - «ловить раков» (от der Krebs «рак»). Das Mädchen krebste im Wasser wie ein alter Fischer (Forster, S. 31)* «- Девочка ловила раков как старый опытный рыбак (здесь и далее перевод наш. - Ю. Г.).

Fischen - «ловить рыбу» (от der Fisch «рыба»). Der Teich sah schmutzig aus als vorher, aber Sylvana ging tapfer hinein und beide fischten (Forster, S. 306) - Пруд выглядел грязным, как и прежде, но Сильвана смело вошла в воду и оба ловили рыбу.

Mäuseln - «ловить мышей, мышковать» (от die Maus «мышь»). Unten hockte regungslos eine Katze und mäuselte. Sie hatte Erfolg, wie an einem kurzen erschrockenen Piepsen zu hören war (Wander, S. 429) - Внизу неподвижно сидела кошка и мышковала. Судя по короткому испуганному писку, охота удалась.

Во вторую группу глаголов первого типа вошли единицы со значением «производить потомство, рождать детеныша», которые в подавляющем большинстве случаев как в немецком, так и в русском языках образованы от номинаций домашних животных.

Например, ferkeln - «пороситься» (от das Ferkel «поросенок»). Die Zuchtsau ferkelt gewöhnlich zweimal im Jahr, und bringt jedes Mal acht bis zwölf Junge zur Welt (Gaitzsch, S. 56) - Племенная свиноматка поросится обьчно дважды в год и каждый раз производит на свет от восьми до двенадиати поросят.

Fohlen - «жеребиться» (от das Fohlen «жеребенок»). Hier weilte damals seine Mutter Aversion zur Bedeckung durch

Источники примеров приведены в перечне после статьи.
Teddy und fohlte noch vorher einen ungewöhnlich schönen und ausdrucksvollen Hengst, der den Namen Alchimist erhielt (Gaitzsch, S. 87) - Здесь его мать жила под гнетом охраны Тедди, но до этого она ожеребила невероятно красивого жеребца, которой получил имя Алхимик.

Kalben - «телиться» (от das Kalb «теленок»). Die Kuh kalbte und brachte ein eisenblaues Kalb zur Welt (Gaitzsch, S. 112) - Корова отелилась, и на свет появился голубоглазый теленок.

Достаточно многочисленную группу составили глаголы второго типа.

Так, нами были обнаружены единицы с метафорическим значением «проявлять какие-л. особенности, характерные для животных». Анализ данных зооглаголов позволил разработать следующую классификацию действий:

1. «Двигаться»: dackeln (от der Dackel «такса») — «неуклюже шагать»; käfern (от der Käfer «жук») — «сновать как жук»; kälben (от das Kalb «теленок») — «резвиться как теленок»; pinschern (от der Pinscher «пинчер, шавка (груб.)») «бежать, нестись»; pudeln (от der Pudel «пудель») «плыть по-собачьи, бежать как собачонка»; robben (от die Robbe «тюлень») - «ползти на животе»; schlängeln (от die Schlange «змея») - «извиваться»; storchen (от der Storch «аист») - «шагать, как аист, как на ходулях»; tigern (от der Tiger «тигр») — «бродить, носиться, сновать»; wieseln (от das Wiesel «ласка») — «семенить, бегать мелкими шажками».

Cp.: Er robbte auf den Ellbogen wie eine Galapagos-Echse auf ihren kurzen Beinen (Heiter, S. 321) - Он ползал на локтях, как галапагосская ящерица на ее коротких ногах.

Frau Stegmann wieselte zwischen Küche und Zimmer in und her, und Klaus wartete bis ich mir einen Platz ausgesucht hatte (Маaß, S. 236) - Миссис Стегманн семенила между кухней и комнатой, а Клаус ждал, пока я не выберу себе место.

2. «Источать запах»: bocken (от der Bock «козел») «смердеть, испускать зловоние»; fischeln (от der Fisch «рыба») - «пахнуть, вонять рыбой»; möpseln (от der Mops «мопс») - «пахнуть псиной, быть с душком».

Lothar nahm noch einen Schluck und stöhnt: „Sie haben Recht! Mein Wein möpselt" (Freund, S. 175) - Jomap cdeлал еще один глоток и простонал: «Вы правы! Мое вино воняет псиной».

Frisch gefangener Fisch fischelt nämlich überhaupt nicht. Erst eine chemische Reaktion nach dem Tod des Tieres führt zum typischen „Duft“ (Gaitzsch, S. 54) - Свежевыловленная рыба не воняет. Только химическая реакция после смерти животного приводит к типичному «аромату».

3. «Издавать звуки»: finken (от der Finken «зяблик») «петь»; gimpeln (от der Gimpel «снегирь») — «насвистывать»; krähen (от die Krähe «ворона») — «каркать, кукарекать; орать, вопить, визжать»; kuckkucken (от der Kuckuck «кукушка») — «куковать»; mäuseln (от die Maus «мышь») — «подражать мышиному писку».

„Was?", krähte Frau Schlecker aus dem Sessel (Held, S. 96) - «Что?», - проорала фррау Шлекер из своего кресла.

Sie ist sehr leicht zu schießen, wenn man ihrem Rufe nachgeht, sich dann in die Nähe stellt und mit dem Munde 
mäuselt (Маaß, S. 95) - Ее очень легко подстрелить, если встать поближе и подражать ее звуку, пищать как мышонку.

4. «Оказывать эмоциональное воздействие»: äffen (от der Affe «обезьяна») - «обезьянничать, дурачить»; belämmen (от das Lamm «ягненок») - «докучать, дурачить, обманывать»; ferkeln (от das Ferkel «поросенок») «напакостить, говорить непристойности»; füchsen (от der Fuchs «лиса») - «обманывать, обижать, злить»; pudeln (от der Pudel «пудель») - «обращаться как с собачонкой»; sauen (от die Sau «свинья, свиноматка») — «пакостить, говорить гадости»; schweinigeln (от das Schwein «свинья») - «рассказывать пошлые анекдоты, похабничать»; spinnen (от die Spinne «паук») - «плести интриги, издеваться»; unken (от die Unke «жерлянка, предвестник беды») - «пророчить беду, каркать»; wurmen (om der Wurm «червь») - «раздражать, злить».

Wer nicht schweinigelt, ist kein Soldat (Remarque, S. 65)Кто не рассказывает пошлые анекдоты, тот не солдат.

Das wurmte mich so sehr, sodass ich eines Tages die Meinung meines Vaters einfach ignorierte und mir einen (wie ich meinte) supermodernen Langhaarschnitt "verpassen“ ließ (Heiter, S. 409) - Это настолько разозлило меня, что однажды я просто проигнорировал мнение моего отца и позволил себе (как я думал) суперсовременную длинную стрижку.

5. «Осуществлять какую-либо деятельность»: büffeln (от der Büffel - «буйвол») - «напряженно работать, пахать»; dachsen (от der Dachs «барсук») - «спать как сурок»; einigeln (от der lgel «еж») — «занимать круговую оборону»; eseln (от der Esel «осел») — «тяжело работать, ишачить»; geiern (от der Geier «коршун») — «выслеживать добычу»; hamstern (от der Hamster «хомяк») — «мешочничать, скупать»; lausen - «грабить, выманивать деньги»; luchsen (от die Laus «вошь») — «следить, подсматривать», maulwurfen (от der Maulwurf «крот») — «рыть»; mullen (от der Mull «крот») — «рыться в земле»; ochsen (от der Ochse «бык») - «пахать как бык».

Sie sitzt in ihrem Zimmer und büffelt. — Was tut sie? — Sie büffelt. Das heißt so, wenn man sich intensiv auf eine Prüfung vorbereitet (Guillion, S. 214) - Она сидит в своей комнате и «nашет». - Что она делает? - Она пашет, то есть напряженно готовится к экзамену.

Bereits an der Gangway werden den Passagieren die ersten Dollars aus der Tasche geluchst (Straten, S. 197) - Уже на проходной у пассажиров украли первые доллары из карманов.

Как мы видим, многие наименования животных породили устойчивые ассоциации с определенными свойствами человека и превратились в символы, которые употребляются для образной характеристики человека [1, с. 22]. Как отмечает В. А. Степаненко, «появление большей части зоонимических метафор тесно связано с жизнедеятельностью людей и основано на своеобразной ассоциации по смежности: то, что имеет место в человеческом обществе, переносится на представителей животного мира» [5, с. 117].

Анализ зооглаголов английского языка показал, что семантика метафрорических зооглаголов указывает на подобие тому или иному представителю животного мира, что способствует возникновению оценки, образности, эмоцио- нальности и экспрессивности. Глаголы, произведенные от названий животных, становятся таким образом средством отражения субъективного понимания и объяснения действительности человеком [6, с. 106]. Приведенные выше примеры немецких зоолексем полностью подтверждают сделанные на другой языковой базе предположения. В дополнение заметим, что большинство вторичных значений глаголов, образованных от названий животных, отмечены в словарях особыми стилистическими пометами: разговорное, просторечное, фрамильярное и др.

Например: reihern (от der Reiher «цапля») — мол. жарг. «болтать глупости»; разг. «блевать» - Ich sprang ins Bad und schon reiherte ich das Essen von heute Abend raus (Steiner, S. 45) - Я побежал в ванну и выблевал весь сегодняшний ужин.

verbocken (от der Bock «козел») - разг. «испортить (что-л.); запороть (дело), облажаться» - Er machte sichkeinerlei Illusionen über sie Leute, für die er arbeitete. Wenn er es verbockte, würden sie ihn wahrscheinlich umbringen. So einfach das war! (Bale, S. 118) - У него не было иллюзий о людях, на которых он работал. Если он облажается, они, вероятно, убьют его. Это было так просто!

ferkeln (от das Ferkel «поросенок») — разг. «испачкать; напакостить; пакостить»; фрам. «говорить непристойности» Er ferkelte aber beim Essen, weil er, ohne die Augen zu senken, blindlings ins Brot biß (Steiner, S. 87) - За едой он испачкался, так как слепо, не опуская глаз, откусывал хлеб.

äffen (от der Affe «обезьяна») — «подражать (кому-л.), обезьянничать, передразнивать»; высок. «дурачить, сбивать с толку» - Und der Junge sprang in seiner Samtbluse umher und äffte alle nach, Mädchen und Jungen, in Stimme und Gebärden, so daß Mutter sich vor Lachen in ihrem Stuhl wand (Bang, S. 51) - Мальчик прыгал в своей бархатной блузке и передразнивал всех, девочек и мальчиков, подражал их голосам и жестам так, что мать корчилась от смеха в своем кресле.

Таким образом, выбирая признаки или свойства животного для характеристики и оценки действий человека, мы выражаем наши собственные чувства и реакции. Зачастую эти признаки могут быть обусловлены не столько качествами самого животного, сколько качествами, которые ему объективно не присущи, а приписываются фантазией человека. При этом зооглаголы в переносном значении довольно редко употребляются для положительной оценки. Более характерным для вторичных значений зооглаголов является их отрицательная коннотация.

В заключение хотелось бы отметить, что перспектива дальнейшего исследования видится в сравнительном анализе метафорического значения зооглаголов в немецком и русском языках, который позволит выявить национальнокультурную специфику взаимодействия образов человека и животного.

1. Гэн Ю. Моделирование лексико-деривационного пространства (на материале русской зоолексики) : дис. ... канд. филол. наук. Екатеринбург, 2018. 238 с.

2. Современный русский язык : учеб. / В. А. Белошапкова, Е. А. Брызгунова, Е. А. Земская [и др.] ; под ред. 
В. А. Белошапковой. 4-е изд., стер. М. : ООО «Издательство "Альянс"», 2011. 928 с.

3. Мультитран: электрон. словарь. URL: https://www. multitran.com (дата обращения: 16.03.2019).

4. PONS: онлайн-словарь. URL: https://ru.pons.com (дата обращения: 16.03.2019).

5. Степаненко В. А. Зоонимы в немецком словоообразовании (к проблеме соотношения сложного слова и словосочетания) : дис. ... канд. фрилол. наук. Иркутск, 1992. 160 с.

6. Бабина Л. В. Английские и русские глаголы, образованные от названий животных, как средство изучения интерпретирующего аспекта познавательных процессов // Вестн. Тамбов. ун-та. Сер. Гуманитарные науки. 2012. № 8. URL: https:/elibrary. ru/item.asp?id=17524118 (дата обращения: 14.03.2019).

\section{Источники примеров}

1. Bang H. Romane und Novellen. Band 4. Berlin : Books on Demand, 2014. $463 \mathrm{~s}$.

2. Bale E. Overkill. München : Goldmann Verlag, 2011. 448 s.

3. Forster S. Dieletzte Amazone. Leipzig : Twentysix, 2016. $434 \mathrm{~s}$.
4. Freund L. Ferienreisemit Rembrandt. Berlin : Christiana, 1970. $264 \mathrm{~s}$.

5. Gaitzsch H. V. Die Birkhans. Story. Leipzig : Engelsdörfer, 2006. $180 \mathrm{~s}$.

6. Guillion J. Schicksalsjahre. München : Wilhelm Heyne 2014. $433 \mathrm{~s}$.

7. Heiter W. Damals in der Rappengasse. Berlin : Books On Demand, 2009. $416 \mathrm{~s}$.

8. Held A. Die letzten Dinge. Düsseldorf : August, 2005. $315 \mathrm{~s}$.

9. Maaß S. Keine Flügel für Reggi. Berlin : Neues Leben, 2011. $240 \mathrm{~s}$.

10. Remarque E.M. Im Westen nichts Neues. Köln : Kiepenheuer \& Witsch, 1971. 215 s.

11. Steiner K. Einelocht. Hamburg : Himmelstürmer, 2006. $220 \mathrm{~s}$.

12. Straten P. Indian Summer. Meine letzte Reise nach Canada. Berlin : Epubli GmbH, 2008. 409 s.

13. Wander D. Simoneta. Bremen : Schünemann, 2004. $524 \mathrm{~s}$.

\section{Немецкие глаголы, образованные от названий животных}

Приложение

\begin{tabular}{|c|c|c|}
\hline $\begin{array}{l}\text { № } \\
\Pi / \Pi\end{array}$ & Глагол и зооним, от которого он образован & Значение \\
\hline 1 & aalen (der Aal - угорь) & общ. ловить угрей; разг. нежиться; развлекаться \\
\hline 2 & äffen (der Affe - обезьяна) & подражать (кому-л.), обезьянничать; высок. дурачить, сбивать с толку \\
\hline 3 & belämmern (das Lamm — ягненок) & надоедать, докучать; обманывать, дурачить \\
\hline 4 & bocken (der Bocke — козел) & $\begin{array}{l}\text { общ. вставать на дыбы (напр., о лошади); бодаться; давать козла (о лошади); про- } \\
\text { тивиться; упорствовать; смердеть; издавать резкий запах; испускать зловоние; } \\
\text { находиться в состоянии течки (об овцах, козах); разг. барахлить; плохо работать } \\
\text { (напр., о двигателе); фам. капризничать; упрямиться; артачиться }\end{array}$ \\
\hline 5 & büffeln (der Büffel - буйвол) & напряженно работать, работать как буйвол; фам. зубрить; долбить \\
\hline 6 & dachsen (der Dachs - барсук) & спать как сурок \\
\hline 7 & dackeln (der Dackel — такса) & неуклюже шагать, медленно ходить; бесцельно проводить время \\
\hline 8 & einigeln, sich (der Igel — еж) & занять круговую оборону; изолироваться, замкнуться в себе \\
\hline 9 & eseln (der Esel - осел) & $\begin{array}{l}\text { диал. совершать глупость; поступать глупо; сглупить; жарг. ишачить; разг. тяжело } \\
\text { работать; работать, не разгибая спины; надрываться; подшучивать (над кем-л.); } \\
\text { дурачить (кого-л.); пахать; горбатиться; работать без разгиба; фам. вкалывать }\end{array}$ \\
\hline 10 & ferkeln (das Ferkel — поросенок) & $\begin{array}{l}\text { общ. опороситься; напачкать; испачкаться; пачкать; мол. жарг. рожать; разг. испач- } \\
\text { кать; напакостить; пакостить; пороситься; фам. говорить непристойности }\end{array}$ \\
\hline 11 & finken (der Fink - зяблик) & петь \\
\hline 12 & fischeln (der Fisch - рыба) & пахнуть, вонять рыбой \\
\hline 13 & fischen (der Fisch - рыба) & общ. ловить рыбу; рыбачить; ловить (рыбу); разг. вылавливать; выуживать \\
\hline 14 & fohlen (das Fohlen - жеребенок) & жеребиться \\
\hline 15 & füchsen (der Fuchsr - лиса) & обманывать; обижать; охотиться на лисиц; разг. сердить; раздражать; злить \\
\hline 16 & füchseln (der Fuchsr — лиса) & охотиться на лис \\
\hline 17 & geiern (der Geier — гриф) & кружить как стервятник над добычей; выслеживать (auf + Akk); следить за добычей \\
\hline 18 & gimpeln (der Gimpe - снегирь) & насвистывать \\
\hline 19 & hamstern (der Hamster — хомяк) & мешочничать; скупать; накапливать; заниматься спекуляцией; хомячить (есть) \\
\hline 20 & igeln (der Igeln — еж) & $\begin{array}{l}\text { воен. занимать круговую оборону (отделения, взвода); подготавливать круговую } \\
\text { оборону (отделения, взвода); подготавливать круговое охранение (отделения, } \\
\text { взвода); мол. жарг. заниматься любовью }\end{array}$ \\
\hline
\end{tabular}


Продолжение приложения

\begin{tabular}{|c|c|c|}
\hline $\begin{array}{l}\text { № } \\
\text { п/п }\end{array}$ & Глагол и зооним, от которого он образован & Значение \\
\hline 21 & kalben (das Kalb - теленок) & $\begin{array}{l}\text { телиться; отелиться; отселиться; отламываться; отрываться (об айсберге); } \\
\text { мол. жарг. рожать (букв. телиться) }\end{array}$ \\
\hline 22 & kälbern (das Kalbr - теленок) & $\begin{array}{l}\text { общ. вести себя по-ребячески; груб. телиться; разг. дурачиться; резвиться (как } \\
\text { теленок) }\end{array}$ \\
\hline 23 & känguruhen (das Känguruhr — кенгуру) & класть новорожденного к себе на живот, грудь — контакт кожа к коже \\
\hline 24 & krebsen (der Krebs - pak) & $\begin{array}{l}\text { общ. ловить раков; бесцеремонно использовать (кого-л.); геол. трескаться; тре- } \\
\text { щать; выделить газ (об ископаемых углях); перен., разг. выкарабкиваться (из труд- } \\
\text { ного положения и т. п.); биться (безуспешно стараться); разг. ползти; карабкаться; } \\
\text { тащиться; пятиться назад }\end{array}$ \\
\hline 25 & krähen (die Krähe - ворона) & $\begin{array}{l}\text { общ. петь; кричать кукареку (о петухе); каркать; петь (о петухе); кукарекать о пету- } \\
\text { хе; детск. агукать, гулить; образн. орать, вопить, кричать, визжать; говорить карка- } \\
\text { ющим/скрипучим голосом; верещать; стрекотать; повизгивать }\end{array}$ \\
\hline 26 & käfern (der Käferr — жук) & бегать; сновать (как жук) \\
\hline 27 & kuckucken (der Kuckuck) — кукушка & куковать \\
\hline 28 & lammen (das Lammr — ягненок) & ягниться \\
\hline 29 & lausen (die Laus - вошь) & $\begin{array}{l}\text { искать вшей (у кого-л.); груб. грабить (кого-л.); выманивать деньги (у кого-л.); фам. } \\
\text { выманивать хитростью деньги (у кого-л.); обирать (кого-л.); основательно обыски- } \\
\text { вать (кого-л.); тщательно обыскивать (кого-л.); шпионить (жарг.) }\end{array}$ \\
\hline 30 & luchsen (der Luchs - рысь) & $\begin{array}{l}\text { внимательно следить; высматривать; украсть; разг. внимательно и незаметно } \\
\text { следить; подсматривать; воровать; стащить }\end{array}$ \\
\hline 31 & mardern (der Marder — куница) & грабить; похищать \\
\hline 32 & maulwurfen (der Maulwurf — крот) & рыть (как крот) \\
\hline 33 & mausen (die Maus - мышь) & $\begin{array}{l}\text { общ. ловить мышей; красться; неслышно пробираться; разг. украсть; фрам. стя- } \\
\text { нуть; стащить }\end{array}$ \\
\hline 34 & mullen (der Mull — крот) & копаться; рыться в земле; крошиться \\
\hline 35 & mäuseln (die Mausr — мышь) & подражать мышиному писку, ловить мышей, мышковать \\
\hline 36 & möpseln (der Mopsr — мопс) & пахнуть псиной; быть с душком \\
\hline 37 & ochsen (der Ochse - вол) & зубрить, усердно работать, пахать как бык \\
\hline 38 & pinschern (der Pinscher - пинчер) & бежать; нестись \\
\hline 39 & pudeln (derPudel — пудель) & $\begin{array}{l}\text { обращаться как с собакой (с кем-л.); плыть по-собачьи; барахтаться (в воде), } \\
\text { бежать как собачонка [как щенок]; семенить }\end{array}$ \\
\hline 40 & rammen (der Ramme - баран) & $\begin{array}{l}\text { общ. забивать (сваи); налетать; совершать наезд (на кого-л.); сталкиваться } \\
\text { (об автомобилях); таранить; трамбовать }\end{array}$ \\
\hline 41 & rammeln (der Ramme - баран) & $\begin{array}{l}\text { общ. спариваться (об овцах, о зайцах и кроликах); возиться; бороться; совокуп- } \\
\text { ляться }\end{array}$ \\
\hline 42 & reihern (der Reiher - цапля) & мол. жарг. болтать глупости; разг. блевать \\
\hline 43 & robben (die Robbe - тюлень) & ползти на животе; ползти по-пластунски \\
\hline 44 & sauen (die Sau - свиноматка) & $\begin{array}{l}\text { общ. грязнить; груб. пакостить; пачкать; плохо работать; говорить сальности; опо- } \\
\text { роситься; говорить гадости; халтурить; пороситься }\end{array}$ \\
\hline 45 & schlängeln (die Schlanger - змея) & $\begin{array}{l}\text { общ. извиваться; изгибаться; виться; пробираться (сквозь толпу и т. п.); петлять; } \\
\text { перен. изворачиваться; лавировать }\end{array}$ \\
\hline 46 & schweinigeln (das Schwein — свинья) & $\begin{array}{l}\text { рассказывать пошлые анекдоты; рассказывать скабрезные истории; говорить } \\
\text { непристойности; рассказывать похабные истории; рассказывать неприличные } \\
\text { анекдоты; груб. свинячить; похабничать }\end{array}$ \\
\hline 47 & sperbern (der Sperber — ястреб) & зорко смотреть; смотреть бдительным оком \\
\hline 48 & spinnen (die Spinne - паук) & $\begin{array}{l}\text { общ. плести (паутину — о пауках); вить (коконы — о шелкопрядах); рехнуться; груб. } \\
\text { офонареть; рехнуться; образн. вешать лапшу на уши; перен. замышлять; плести } \\
\text { (интриги, заговор и т. п.); сойти с ума; разг. франтазировать; говорить небылицы; } \\
\text { разг. издеваться, прикалываться }\end{array}$ \\
\hline 49 & stieren (der Stier - бык) & уставиться (на кого-л., на что-л.); неистовствовать; выпучить глаза; \\
\hline 50 & storchen (der Storch - аист) & шагать как аист, как журавль, как на ходулях \\
\hline 51 & tigern (der Tiger - тигр) & $\begin{array}{l}\text { общ. делать пестрым; мол. жарг. дождаться (своего часа); подстерегать (удачу); } \\
\text { прошвырнуться; разг. сновать; спец. красить под цвет тигровой шкуры; текст. кра- } \\
\text { сить под тигровую шкуру; фрам. бродить; носиться }\end{array}$ \\
\hline
\end{tabular}


Окончание приложения

\begin{tabular}{|c|l|l|}
\hline $\begin{array}{c}\text { № } \\
\mathbf{n} \mathbf{n}\end{array}$ & Глагол и зооним, от которого он образован & \multicolumn{1}{c|}{ Значение } \\
\hline $\mathbf{5 2}$ & $\begin{array}{l}\text { unken (die Unke - жерлянка; } \\
\text { разг. предвестник беды) }\end{array}$ & пророчить беду; каркать \\
\hline $\mathbf{5 3}$ & verbocken (der Bock - козел) & разг. испортить (что-л.); запороть (дело) \\
\hline $\mathbf{5 4}$ & vögeln (der Vogelr - птица) & груб. спариваться (о людях) \\
\hline $\mathbf{5 5}$ & walen (der Wal - кит) & рыскать (о корабле) \\
\hline $\mathbf{5 6}$ & wieseln (das Wiesel - ласка) & семенить; бегать мелкими шажками \\
\hline $\mathbf{5 7}$ & wölfen (der Wolfr - волк) & щениться (тж. о волчице, лисе) \\
\hline $\mathbf{5 8}$ & wurmen (der Wurm - червь) & общ. раздражать; лес. точить (о червях); мед. быть раздраженным \\
\hline
\end{tabular}

(C) Горюнова Ю. Н., 2019

УДК $811^{`} 25$

Науч. спец. 10.02.20

DOI: 10.36809/2309-9380-2019-24-79-82

\section{ТРУДНОСТИ ПЕРЕВОДА НА РУССКИЙ ЯЗЫК АВТОРСКИХ ПАРАЛЛЕЛИЗМОВ В РОМАНЕ \\ П. ЗЮСКИНДА «ПАРФЮМЕР. ИСТОРИЯ ОДНОГО УБИЙЦЫ»}

В статье представлены трудности, с которыми сталкивается переводчик при переводе художественных повторов разных языковых уровней в оригинальном тексте. Анализируются также способы решения этой задачи в переводческой практике.

Ключевые слова: параллелизм, идиостиль, структурносемантическая трансформация, коннотация, аллитерация, анафора, эпифора.
Н. М. Киселева

N. M. Kiseleva

The article presents the difficulties faced by the translator in translating literary repetitions of different language levels in the original text. The ways of solving this problem in translation practice are also analyzed.

Keywords: parallelism, idiostyle, structural-semantic transformation, connotation, alliteration, anaphora, epiphora.

Изучение популярного, вызвавшего невероятный резонанс романа «Das Parfum. Die Geschichte eines Mörders» (в русском переводе - «Парфюмер. История одного убийцы» (1985)) современного немецкого автора Патрика Зюскинда [1] проводится в последние десятилетия в разных научных направлениях. Литературоведы оценивают жанровую принадлежность нашумевшего произведения, переведенного на 39 языков мира, изданного десятимиллионным тиражом. По мнению большинства экспертов, произведение Зюскинда создано в традициях постмодернизма, использующего разностилевые черты прошлого, представляющего собой своего рода «литературный розыгрыш, игру намеков, двойное и тройное кодирование, хроническое переосмысливание и литературную симуляцию» [2, с. 24]. Так, Ю. Райан видит в романе П. Зюскинда пародию на литературу романтизма [3, р. 396]. Не остается без внимания критиков проблема отношений злого гения и «толпы» $[4$, с. 9], в ходе бесконечной интерпретации которой высказывается любопытная мысль о возможной авторской аллюзии на Третий рейх [5, р. 223]. И. Л. Галинская относит историю о Жан-
Батисте Гренуе, одаренном маньяке, посвятившем свою недолгую жизнь поиску божественного аромата, сотканного из нежных запахов убитых им 25 невинных девушек, к криминальной литературе [6, с. 75].

Не менее интересен роман для концептуальной лингвистики, анализирующей детальную репрезентацию концепта «запах», всей палитры ольфакторных ощущений, так удивительно полно переданных автором [7]. Наконец, стилисты не перестают восхищаться мастерским владением художественным словом и многообразием использованных П. Зюскиндом в романе средств выразительности [8].

Последняя деталь, языковая специфика идиостиля автора, нуждается также в переводческом анализе, поскольку большая часть читателей имеют возможность познакомиться с бестселлером П. Зюскинда только на языке перевода. В рамках настоящей статьи будут рассмотрены способы и трудности передачи на русский язык разноуровневых параллелизмов, многообразных языковых повторов, играющих в стилистике романа, безусловно, важную контекстуальную роль, являющихся одним из заметнейших приемов 